\title{
Selective albumin-binding surfaces modified with a thrombin-inhibiting peptide
}

\author{
Sidónio C. Freitas ${ }^{\mathrm{a}, \mathrm{b}}$, Sílvia Maia ${ }^{\mathrm{c}}$, Ana C. Figueiredo ${ }^{\mathrm{d}}$, Paula Gomes ${ }^{\mathrm{c}}$, Pedro J.B. Pereira ${ }^{\mathrm{d}}$, \\ Mário A. Barbosa ${ }^{\text {a,e }}$, M. Cristina L. Martins ${ }^{\mathrm{a}, \mathrm{e}, *}$ \\ a INEB - Instituto de Engenharia Biomédica, Universidade do Porto, Rua do Campo Alegre 823, 4150-180 Porto, Portugal \\ ${ }^{\mathrm{b}}$ Universidade do Porto, Faculdade de Engenharia, Rua Dr. Roberto Frias s/n, 4200-465 Porto, Portugal \\ ${ }^{\mathrm{C}}$ CIQ-UP - Departamento de Química e Bioquímica, Faculdade de Ciências, Universidade do Porto, Rua do Campo Alegre 687, 4169-007 Porto, Portugal \\ ${ }^{\mathrm{d}}$ IBMC - Instituto de Biologia Molecular e Celular, Universidade do Porto, Rua do Campo Alegre 823, 4150-180 Porto, Portugal \\ e Universidade do Porto, Instituto de Ciências Biomédicas Abel Salazar, Rua de Jorge Viterbo Ferreira 228, 4050-313 Porto, Portugal
}

\section{A R T I C L E I N F O}

Article history:

Received 13 August 2013

Received in revised form 13 November 2013

Accepted 25 November 2013

Available online 5 December 2013

\section{Keywords:}

Blood compatibility

Clotting

Surface modification

Thrombin

Albumin

\begin{abstract}
A B S T R A C T
Blood-contacting medical devices have been associated with severe clinical complications, such as thrombus formation, triggered by the activation of the coagulation cascade due to the adsorption of certain plasma proteins on the surface of biomaterials. Hence, the coating of such surfaces with antithrombotic agents has been used to increase biomaterial haemocompatibility. Biomaterial-induced clotting may also be decreased by albumin adsorption from blood plasma in a selective and reversible way, since this protein is not involved in the coagulation cascade. In this context, this paper reports that the immobilization of the thrombin inhibitor D-Phe-Pro-D-Arg-D-Thr- $\mathrm{CONH}_{2}$ (fPrt) onto nanostructured surfaces induces selective and reversible adsorption of albumin, delaying the clotting time when compared to peptide-free surfaces. fPrt, synthesized with two glycine residues attached to the N-terminus (GGfPrt), was covalently immobilized onto self-assembled monolayers (SAMs) having different ratios of carboxylate-hexa(ethylene glycol)- and tri(ethylene glycol)-terminated thiols (EG6-COOH/EG3) that were specifically designed to control GGfPrt orientation, exposure and density at the molecular level. In solution, GGfPrt was able to inactivate the enzymatic activity of thrombin and to delay plasma clotting time in a concentration-dependent way. After surface immobilization, and independently of its concentration, GGfPrt lost its selectivity to thrombin and its capacity to inhibit thrombin enzymatic activity against the chromogenic substrate $n$ - $p$-tosyl-Gly-Pro-Arg- $p$-nitroanilide. Nevertheless, surfaces with low concentrations of GGfPrt could delay the capacity of adsorbed thrombin to cleave fibrinogen. In contrast, GGfPrt immobilized in high concentrations was found to induce the procoagulant activity of the adsorbed thrombin. However, all surfaces containing GGfPrt have a plasma clotting time similar to the negative control (empty polystyrene wells), showing resistance to coagulation, which is explained by its capacity to adsorb albumin in a selective and reversible way. This work opens new perspectives to the improvement of the haemocompatibility of blood-contacting medical devices.
\end{abstract}

( 2013 Acta Materialia Inc. Published by Elsevier Ltd. All rights reserved.

\section{Introduction}

Failure of some blood-contacting medical devices has been associated with thrombus formation initiated by the adsorption of certain blood proteins onto the biomaterial surface. This protein layer can induce complex and interlinked processes, such as activation of the intrinsic coagulation system and adhesion and activation of platelets [1]. Thrombin is a key proteolytic

* Corresponding author at: INEB - Instituto de Engenharia Biomédica, Universidade do Porto, Rua do Campo Alegre 823, 4150-180 Porto, Portugal. Tel.: +351 22 6074982; fax: +351226094567.

E-mail address: cmartins@ineb.up.pt (M. Cristina L. Martins). enzyme of the coagulation cascade since it catalyses the conversion of soluble fibrinogen into fibrin, a major and essential component of the blood clot. This protease also activates FXIII, which cross-links and stabilizes the fibrin mesh, induces platelet activation and stimulates its own generation supporting blood clotting [2]. Heparin, an indirect thrombin inhibitor, has been widely used as a systemic anticoagulant and as a coating of medical devices to delay biomaterial-induced thrombosis $[3,4]$. However, heparin only inhibits thrombin after its binding to endogenous antithrombin (AT), which may be reduced in patients having AT deficiency or sepsis [5]. Moreover, nonspecific heparin binding to plasma proteins (i.e. fibrinogen) and to proteins secreted by platelets (i.e. platelet factor 4 (PF4)) not only decreases its 
availability to bind AT but can also lead to side-effects such as thrombocytopenia induced by heparin-PF4 complexes. In addition, the heparin-AT complex does not inhibit fibrin-bound thrombin [6,7].

Alternatively, direct thrombin inhibitors directly block the active site of both soluble and fibrin-bound thrombin and do not require the presence of an endogenous cofactor [6]. Hirudin, a highly potent and specific natural thrombin inhibitor [8], has also been explored as a biomaterials coating but its low biological activity and stability after surface immobilization limits its utilization for short-term applications [9-13].

Small peptides have several advantages over biomolecules (i.e. proteins) to be used as a biomaterials coating: (1) easier and less expensive production; (2) greater stability (longer shelf-life); (3) generally, lower immunogenicity [14]; (4) more controllable coupling to the surface [15]. Small synthetic direct thrombin inhibitor peptides containing the amino acid sequence D-Phe-Pro-Arg, which resembles the specific thrombin binding of human fibrinopeptide A [16], have also been explored [17-19]. The small peptide, D-Phe-Pro-Arg-Pro-Gly (fPRPG) [20], which was previously immobilized by us onto ethylene glycol (EG)-terminated selfassembled monolayers (SAMs), inhibited the activity of adsorbed thrombin in a concentration-dependent way but lost most of its thrombin-binding selectivity in the presence of plasma proteins [18]. The direct and irreversible thrombin inhibitor, D-Phe-Pro$\mathrm{ArgCH}_{2} \mathrm{Cl}$ (PPACK), was also recently immobilized onto poly(propylene-alt-maleic anhydride) (PPMA) thin films using EG as a spacer [19]. Nevertheless, most of the PPACK molecules lost their thrombin inhibitory capacity after immobilization, prompting us to develop a new immobilization strategy, which is presented thereafter.

Several small synthetic peptides with the general formula D-Phe(P3)-Pro(P2)-D-Arg(P1)-P1'-CONH ${ }_{2}$, with different D- and L-amino acids at $\mathrm{P} 1^{\prime}$ position, were evaluated for their ability to interact with the thrombin active site and block its proteolytic activity [21-24]. The D-Phe and Pro residues in positions P3 and P2 interact with thrombin S3 and S2 pockets, respectively $[23,25]$. The D-configuration of Arg at the P1 position was used to avoid the proteolytic cleavage of the Arg-P1' bond. D-Phe-Pro-DArg-D-Thr- $\mathrm{CONH}_{2}$ (fPrt) displayed the highest thrombin inhibitory activity [23]. Moreover, this peptide was able to completely inhibit thrombin-induced platelet aggregation $[22,26]$.

This work aims at determining if fPrt can be used as a coating to avoid biomaterials-induced blood coagulation. fPrt was extended at its N-terminal end by two glycines (GGfPrt) to provide a small spacer and to improve its exposure after surface immobilization. GGfPrt was evaluated regarding thrombin enzymatic inactivation and plasma coagulation before and after immobilization onto nanostructured surfaces, prepared by mixing long-chain carboxylate-hexa(ethylene glycol)-terminated thiol (EG6-COOH) with short-chain tri(ethylene glycol)-terminated thiol (EG3). EG3 was used to resist non-specific protein adsorption [27] and the longchain EG6- $\mathrm{COOH}$ to provide $\mathrm{COOH}$ terminal groups to facilitate peptide coupling by its $\mathrm{N}$-terminus with a better surface exposure (Scheme 1). Different concentrations of immobilized GGfPrt were obtained using SAMs prepared with different ratios of EG6$\mathrm{COOH} / \mathrm{EG} 3$.

Surfaces were characterized using ellipsometry, infrared reflection absorption spectroscopy (IRRAS) and X-ray photoelectron spectroscopy (XPS). Protein adsorption was followed using ${ }^{125}$ I-labelled proteins. The effect of GGfPrt on thrombin proteolytic activity was evaluated by assessing the protease ability to cleave the chromogenic substrate $n$ - $p$-tosyl-Gly-Pro-Arg- $p$-nitroanilide and fibrinogen in solution. The anticlotting capacity of the developed surfaces was evaluated using the recalcified plasma clotting assay.

\section{Materials and methods}

\subsection{GGfPrt synthesis}

\subsubsection{Materials and instrumentation}

General solvents and reagents were all of analytical quality and acquired from Sigma-Aldrich (Madrid, Spain). Fmoc-protected amino acids, Fmoc-Rink Amide-MBHA LL resin $\left(0.36 \mathrm{mmol} \mathrm{g}^{-1}\right)$ and coupling reagent $O$-(benzotriazol-1-yl)$N, N, N^{\prime}, N^{\prime}$-tetramethyluronium-hexaflurophosphate (HBTU) were provided by Novabiochem (VWR International, Portugal). Peptide synthesis was performed on a Liberty1 Microwave Peptide Synthesizer (CEM Corporation, Mathews, NC, USA). Peptide analysis by high-performance liquid chromatography (HPLC) was done on a Hitachi-Merck LaChrom Elite system equipped with a quaternary pump, a thermostatted (Peltier effect) automated sampler and a diode-array detector (DAD). An LCQ-DecaXP LC-MS system from ThermoFinnigan, equipped with both a DAD detector and an electrospray ionization-ion trap mass spectrometer (ESI/IT MS), was used also for peptide analysis. Peptide amino acid composition determination was performed by amino acid analysis (AAA) on a Biochrom 30 (CCiT, University of Barcelona).

\subsubsection{Peptide synthesis}

The hexapeptide ( $C$-terminal amide) was assembled by Fmoc/ tBu solid-phase peptide synthesis methodologies assisted with microwave (MW) energy [28,29]. The resin was pre-conditioned for 15 min in $N, N$-dimethylformamide (DMF) and then transferred into the MW-reaction vessel. The initial Fmoc deprotection step was carried out using 20\% piperidine in DMF containing $0.1 \mathrm{M}$ of 1-hydroxybenzotriazole (HOBt) in two MW irradiation pulses: $30 \mathrm{~s}$ at $24 \mathrm{~W}$ plus $3 \mathrm{~min}$ at $28 \mathrm{~W}$, in both cases the temperature did not exceed $75^{\circ} \mathrm{C}$. The $\mathrm{C}$-terminal amino acid was then coupled to the deprotected Rink Amide resin, using $5 \mathrm{M}$ equivalents (eq) of the Fmoc-protected amino acid in DMF $(0.2 \mathrm{M}), 5$ eq of $0.5 \mathrm{M}$ HBTU/HOBt in DMF and 10 eq of $2 \mathrm{M} \mathrm{N}$-ethyl- $\mathrm{N}, \mathrm{N}$-diisopropylamine (DIPEA) in $N$-methylpyrrolidone (NMP); the coupling step was carried out for $5 \mathrm{~min}$ at $20 \mathrm{~W}$ MW irradiation, with maximum temperature reaching $75^{\circ} \mathrm{C}$. The remaining amino acids were sequentially coupled in the $C \rightarrow N$ direction by means of similar deprotection and coupling cycles, except for incorporation of Fmoc-D-Arg(Pbf)-OH, whose coupling was done in two steps: 25 min with no MW irradiation (room temperature, RT) followed by 5 min coupling at $25 \mathrm{~W}$.

Following completion of sequence assembly, the peptide was released from the resin, with concomitant removal of side-chain protecting groups, by a $3 \mathrm{~h}$-acidolysis at RT using a trifluoroacetic acid (TFA)-based cocktail [28] containing water and triisopropysilane (TIS) as scavengers (TFA/ $\mathrm{H}_{2} \mathrm{O} / \mathrm{TIS}$ 95:2.5:2.5 v/v/v). Crude product was purified by reverse-phase liquid chromatography to give the target peptide, as confirmed by HPLC, LC-ESI/IT MS and AAA.

\subsection{Surface preparation}

\subsubsection{Gold substrates}

2.2.1.1. Gold plate. Gold substrates $\left(1 \times 1 \mathrm{~cm}^{2}\right)$ for surface characterization were prepared as described elsewhere [30]. Briefly, chromium $(5 \mathrm{~nm})$ and gold $(25 \mathrm{~nm})$ films were deposited by ion beam sputtering onto silicon wafers. The thin layer of chromium was used to improve adhesion of gold to silicon.

2.2.1.2. Gold wires. For protein adsorption and clotting assays, 99.99\% purity gold wires (Goodfellow Cambridge Ltd) $0.20 \mathrm{~mm}$ in diameter and $30 \mathrm{~cm}$ total length were used. These wires were 


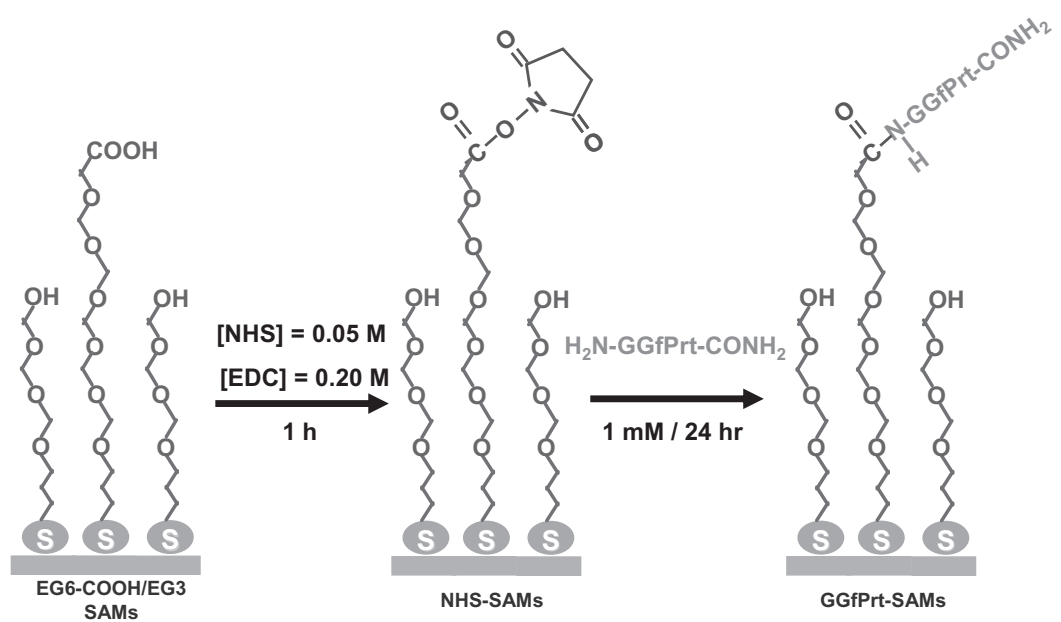

Scheme 1. Schematic representation of GGfPrt immobilization onto mixed EG6/EG3-SAMs.

coiled to fit into the wells of 96-well plates without interfering with the optical path of the microplate spectrophotometer light beam, enabling the real time follow-up of thrombin activity and clotting time. An additional reason for using gold wires was avoiding the interference of the silicon surface on the opposite side of gold planar substrates during immersion assays. Previous electrochemical studies performed by us [31] demonstrated that SAMs prepared in gold wires are as well organized and reproducible as those on planar substrate.

\subsubsection{Preparation of mixed SAMs (EG6-COOH/EG3)}

Pure solutions of (1-Mercapto-11-undecyl)tri(ethylene glycol) (EG3; $\mathrm{SH}-\left(\mathrm{CH}_{2}\right)_{11}\left(\mathrm{OCH}_{2} \mathrm{CH}_{2}\right)_{3}-\mathrm{OH} ; 99 \%$, SensoPath Technologies, Inc.) and (1-Mercapto-11-undecyl)hexa(ethylene glycol) carboxylic acid (EG6-COOH; $\mathrm{SH}-\left(\mathrm{CH}_{2}\right)_{11}\left(\mathrm{OCH}_{2} \mathrm{CH}_{2}\right)_{6}-\mathrm{OCH}_{2} \mathrm{COOH}$; $99 \%$, SensoPath Technologies, Inc.) were prepared at a concentration of $2 \mathrm{mM}$ in absolute ethanol. Mixtures of the EG3 and EG6-COOH-terminated thiols were obtained by mixing the pure solutions in different ratios at final concentrations of $1 \mathrm{mM}$. All solutions were prepared under dry nitrogen atmosphere inside a glove box.

Immediately before being used, gold substrates (plates and wires) were cleaned with a freshly prepared "piranha" solution (7 parts concentrated $\mathrm{H}_{2} \mathrm{SO}_{4}(95 \%(\mathrm{v} / \mathrm{v})$, BDH Prolabo) and 3 parts $\mathrm{H}_{2} \mathrm{O}_{2}(30 \%(\mathrm{v} / \mathrm{v})$, Merck)) for 5 and $30 \mathrm{~min}$, respectively (Caution: this solution reacts violently with many organic materials and should be handled with great care). Then, gold substrates were rinsed sequentially with absolute ethanol (99.9\% (v/v), Merck), Milli-Q water and absolute ethanol for $3 \mathrm{~min}$ in an ultrasound bath and dried with a stream of argon.

Gold substrates were immersed in the alkanethiol solutions and incubated at RT for $24 \mathrm{~h}$ under nitrogen environment. Obtained SAMs were washed twice in absolute ethanol for $2 \mathrm{~min}$ in an ultrasound bath, dried with a stream of nitrogen and maintained in an argon environment inside a sealed petri dish until use.

\subsubsection{GGfPrt immobilization on mixed SAMs}

GGfPrt was immobilized on mixed SAMs in two sequential reaction steps as described in Scheme 1.

2.2.3.1. Activation of the $\mathrm{COOH}$ groups of mixed SAMs. Mixed SAMs were immersed in a freshly prepared Milli-Q water solution of NHS ( $N$-hydroxysuccinimide, Sigma) and EDC (1-(3-dimethylaminopropyl)- $N$-ethylcarbodiimide hydrochloride, Sigma) at a final concentration of 0.05 and $0.20 \mathrm{M}$, respectively. After $1 \mathrm{~h}$ at RT and static conditions, NHS-activated SAMs were washed three times with Milli-Q water and dried with a stream of argon.

2.2.3.2. Immobilization of peptide (GGfPrt) onto NHS-activated SAMs. NHS-activated SAMs were immersed in a $1 \mathrm{mM}$ GGfPrt solution prepared in sodium phosphate buffer $(25 \mathrm{mM}, \mathrm{pH} 8.0)$ for $24 \mathrm{~h}$ at RT and $100 \mathrm{rpm}$. As control, the same reaction was performed without the peptide (only phosphate buffer). All the solutions were kept under nitrogen atmosphere. After immobilization, SAMs were washed three times with Milli-Q water for $5 \mathrm{~min}$ at $150 \mathrm{rpm}$ and RT, dried with a stream of pure argon and preserved in an argon environment until use.

\subsection{Surfaces characterization}

\subsubsection{Ellipsometry}

Monolayers thickness was determined using an EP3 Imaging Ellipsometer (Nanofilm Surface Analysis). This ellipsometer was operated in a polarizer-compensator-sample-analyser (PCSA) mode (null ellipsometry). The light source was a solid-state laser with a wavelength of $532 \mathrm{~nm}$. The gold substrate refractive index $(n)$ and extinction coefficient $(k)$ were determined using a delta and psi spectrum with a variation angle between $66^{\circ}$ and $76^{\circ}$. These measurements were made in four zones to correct for any instrument misalignment. To determine the thickness of the SAMs, the same kind of spectrum was used and $n$ and $k$ for the organic layer were set as 1.45 and zero, respectively.

\subsubsection{Infrared reflection absorption spectroscopy (IRRAS)}

IRRAS measurements were performed on a FTIR spectrophotometer (model 2000, Perkin Elmer) coupled with VeeMax II Accessory (PIKE) and a liquid-nitrogen-cooled MCT detector. The instrument was continuously purged with dry nitrogen for $3 \mathrm{~min}$ before data collection and during measurements to eliminate water vapor absorption. For each SAM, a gold surface was used as the background. The incident light was p-polarized and spectra were collected using the $80^{\circ}$ grazing angle reflection mode. For each sample and reference, 100 scans were collected with $4 \mathrm{~cm}^{-1}$ resolution. Before IRRAS measurements, all SAMs were placed in a vacuum chamber overnight to avoid water absorption.

\subsubsection{X-ray photoelectron spectroscopy (XPS)}

XPS measurements were carried out at CEMUP (Centro de Materiais da Universidade do Porto) on a VG Scientific ESCALAB 200A (UK) spectrometer using magnesium $\mathrm{K} \alpha(1253.6 \mathrm{eV})$ as radiation 
source. The photoelectrons were analysed at a take-off angle of $55^{\circ}$. Survey spectra were collected over a range of $0-1150 \mathrm{eV}$ with an analyser pass energy of $50 \mathrm{eV}$. High-resolution $\mathrm{C}(1 \mathrm{~s}), \mathrm{O}(1 \mathrm{~s}), \mathrm{N}(1 \mathrm{~s})$, $\mathrm{S}(2 \mathrm{p})$ and $\mathrm{Au}(4 \mathrm{f})$ spectra were collected with an analyser pass energy of $20 \mathrm{eV}$. The effect of the electric charge was corrected by the reference of the carbon peak $(285 \mathrm{eV})$. The binding energy (BE) scales were referenced by setting the $\mathrm{Au}_{4 \mathrm{f} 7 / 2} \mathrm{BE}$ to $84.0 \mathrm{eV}$. All the spectra were fitted using an XPS peak fitting program (XPSPEAK Version 4.1). All the carbon spectra were fitted using asymmetrical 70\% Gaussian/30\% Lorentzian profiles.

\subsection{Protein adsorption studies}

\subsubsection{Protein radiolabelling}

Quantification of adsorbed protein on the different monolayers was performed using ${ }^{125}$ I-labelled proteins. Human $\alpha$-thrombin (Haematologic Technologies Inc., $1 \mathrm{mg} \mathrm{m}^{-1}$ in $50 \mathrm{mM}$ sodium phosphate, $150 \mathrm{mM}$ sodium chloride, $\mathrm{pH} 6.5$; $3961 \mathrm{U} \mathrm{mg}^{-1}$ ) and human serum albumin (HSA; Sigma-Aldrich, Ref. A3782) were labelled using the iodogen method [32] as previously described [18]. The yield of the iodination reaction was $97 \%$ for thrombin and $96 \%$ for HSA as determined by the precipitation of the ${ }^{125}$ I-labelled proteins with $20 \%$ trichloroacetic acid (TCA, Merck). ${ }^{125}$ I-labelled proteins were added to unlabelled protein solutions (thrombin, HSA, human plasma or serum) in PBSI ( $0.01 \mathrm{M}$ phosphate buffered saline (PBS) with $0.01 \mathrm{M}$ of $\mathrm{NaI}$ ) in order to achieve a final thrombin activity of $1.5 \times 10^{9} \mathrm{cpm} \mathrm{mg}^{-1}$ and a final HSA activity of $5 \times 10^{7}-$ $\mathrm{cpm} \mathrm{mg}^{-1}$. These activities are higher than those previously used by us $[18,33]$ and the percentage of labelled to unlabelled protein used (20\%) was similar to that described by others [17]. Moreover, these labelled solutions were prepared using the minimum cpm by $\mathrm{mg}$ of unlabelled protein necessary to detect at least $100 \mathrm{cpm}$ per sample. PBSI was used to suppress the binding of free ${ }^{125} \mathrm{I}^{-}$ion (present in trace amounts relative to nonradioactive iodide) as previously described [34-37].

\subsubsection{Protein adsorption on surfaces}

Each gold and SAMs wire was placed in a single well of 96-well plates (polystyrene non-treated microplate, non-binding, Greiner Bio-One), previously filled with $100 \mu \mathrm{l}$ PBSI to completely cover the sample. PBSI was used to avoid the adsorption of free 125-iodine to gold that could interfere with results. After $30 \mathrm{~min}$ of equilibration with PBSI, $100 \mu$ l protein solutions (twofold concentrated in PBSI) were added to each well, resulting in a final $20 \mu \mathrm{g} \mathrm{ml}^{-1} \mathrm{hu}-$ man thrombin solution (corresponding to approximately half of prothrombin concentration in human plasma (978 nM) $[38,39]$ ) or $400 \mu \mathrm{g} \mathrm{ml}^{-1} \mathrm{HSA}$ solution ( 1\% of albumin concentration in human plasma [39]). Protein adsorption was carried out at $37^{\circ} \mathrm{C}$ for $30 \mathrm{~min}$. After adsorption, samples were rinsed three times with PBS and gamma activities were counted inside radioimmunoassay tubes. Surface protein concentration was calculated using the following equation:

$\operatorname{Protein}\left(\mu \mathrm{g} / \mathrm{m}^{2}\right)=\frac{\text { Counts }(\mathrm{cpm}) \cdot C_{\text {solution }}(\mu \mathrm{g} / \mathrm{ml})}{A_{\text {solution }}(\mathrm{cpm} / \mathrm{ml}) \cdot \mathrm{SA}\left(\mathrm{m}^{2}\right)}$

where Counts are the radioactivity measurements from the surface, $C_{\text {solution }}$ and $A_{\text {solution }}$ are the concentration and the specific activity of the protein solution, respectively, and SA is the wire surface area.

\subsubsection{Competitive adsorption studies}

To evaluate the selectivity of GGfPrt-SAMs towards thrombin or HSA in the presence of serum or plasma proteins, the following competitive studies were conducted: (a) Adsorption of ${ }^{125} \mathrm{I}$-thrombin $\left(20 \mu \mathrm{g} \mathrm{ml}^{-1}\right)$ in PBS and ${ }^{125} \mathrm{I}$ thrombin $\left(20 \mu \mathrm{g} \mathrm{ml}^{-1}\right)$ in $1 \%$ human serum. Human serum (PAA Laboratories) was prepared from citrated plasma containing all clotting factors except fibrinogen.

(b) Adsorption of ${ }^{125}$ I-HSA ( $\left.400 \mu \mathrm{g} \mathrm{ml}^{-1}\right)$ in PBS and ${ }^{125} \mathrm{I}-\mathrm{HSA}$ $\left(400 \mu \mathrm{g} \mathrm{ml}^{-1}\right)$ in $1 \%$ citrated human plasma (containing $\sim 400 \mu \mathrm{g} \mathrm{ml}^{-1}$ albumin [39]). Citrated human plasma was prepared from blood obtained from the Portuguese Blood Institute (IPS) according to their guidelines and as previously reported [40].

\subsubsection{Exchangeability studies}

Exchangeability tests were carried out by immersing the surfaces with pre-adsorbed ${ }^{125} \mathrm{I}$-thrombin (30 min pre-adsorption as described in Section 2.4.2) in human serum or with pre-adsorbed ${ }^{125} \mathrm{I}$-HSA in citrated human plasma, at $37^{\circ} \mathrm{C}$ for $24 \mathrm{~h}$. Samples were then rinsed three times with $\mathrm{PBS}$ and residual radioactivity was counted.

\subsection{Thrombin activity studies}

\subsubsection{Effect of soluble GGfPrt on thrombin activity}

The ability of the GGfPrt hexapeptide to inhibit thrombin hydrolytic activity in solution was determined by UV-Vis spectrophotometry (Biotek PowerWave HT microplate spectrophotometer, model: RPRWI340/96) using the chromogenic substrate $n$-p-tosyl-Gly-Pro-Arg-p-nitroanilide (Sigma) [41]. Thrombin solution (5.34 $\mathrm{nM})$ and peptide solutions $(5.34 \mu \mathrm{M}-2 \mathrm{mM})$ were pre-incubated for $15 \mathrm{~min}$ at $37^{\circ} \mathrm{C}$ in 96-well plates. After incubation, the chromogenic substrate was added at a final concentration of $160 \mu \mathrm{M}$. The reaction was followed by measuring the variation of the absorbance at $405 \mathrm{~nm}$ every $15 \mathrm{~s}$ for at least $5 \mathrm{~min}$. All solutions were prepared in PBS.

\subsubsection{Activity of the surface adsorbed thrombin}

The activity of surface adsorbed thrombin was determined by measuring its capacity to cleave the chromogenic substrate $n$ - $p$-tosyl-Gly-Pro-Arg- $p$-nitroanilide and to cleave fibrinogen to fibrin. Surfaces with pre-adsorbed thrombin (prepared as described in Section 2.4.2) were placed in 96-well plates and incubated at $37{ }^{\circ} \mathrm{C}$ with: (1) the chromogenic substrate $(5.34 \mathrm{mM}$ in PBS) or (2) fibrinogen ( $4 \mathrm{mg} \mathrm{ml}^{-1}$ in PBS, corresponding to the upper concentration of the normal range of fibrinogen in human plasma [39]). The absorbance of solutions was followed at $405 \mathrm{~nm}$ every $30 \mathrm{~s}$ for at least $2 \mathrm{~h}$.

The activity of adsorbed thrombin to cleave the chromogenic substrate was quantified in terms of reaction rate $\left(\right.$ abs $\left.\mathrm{min}^{-1}\right)$.

Fibrinogen clotting by adsorbed thrombin was detected by a sharp increase in absorbance. Fibrinogen clotting time was identified as the time when the measured value of absorbance was 0.002 units larger than the average of the measurements from the previous 2 min.

\subsection{Recalcified plasma clotting time assay}

The recalcified plasma clotting time was determined using the spectrophotometric detection method previously described [40]. Briefly, calcium $\left(\mathrm{CaCl}_{2}\right)$ to a final concentration of $20 \mathrm{mM}$ was added to the citrated human plasma, pre-warmed at $37^{\circ} \mathrm{C}$, quickly mixed in a vortex and rapidly added to 96-well plates with GGfPrt or the different surfaces. Absorbance at $405 \mathrm{~nm}$ was measured every $30 \mathrm{~s}$ for $60 \mathrm{~min}$ in the spectrophotometer at $37^{\circ} \mathrm{C}$. A sharp increase in absorbance indicates the start of clot formation. Clotting time was defined as the time span from the beginning of the assay until the moment the measured value of absorbance was 
0.02 units larger than the average of the two previous measurements.

\subsection{Statistical analysis}

The experimental results are presented as the mean \pm the standard deviation (SD). The statistical significance of differences between mean values was determined using the ANOVA one-way test and comparison between groups was performed using the Tukey method. Values of $p<0.05$ were considered statistically significant.

\section{Results}

\subsection{GGfPrt effect on thrombin activity and clotting time}

In solution, GGfPrt was able to inhibit the proteolytic activity of thrombin in a concentration-dependent manner (Fig. 1a). Thrombin activity was almost completely inhibited after pre-incubation with 1 or $2 \mathrm{mM}$ of GGfPrt (GGfPrt/thrombin of $2 \times 10^{5}$ and $4 \times 10^{5}$, respectively). Further, a dose-dependent increase of plasma clotting time by GGfPrt in solution could be observed (Fig. 1b), with values higher than $1 \mathrm{~h}$ for a GGfPrt concentration of $2 \mathrm{mM}$.
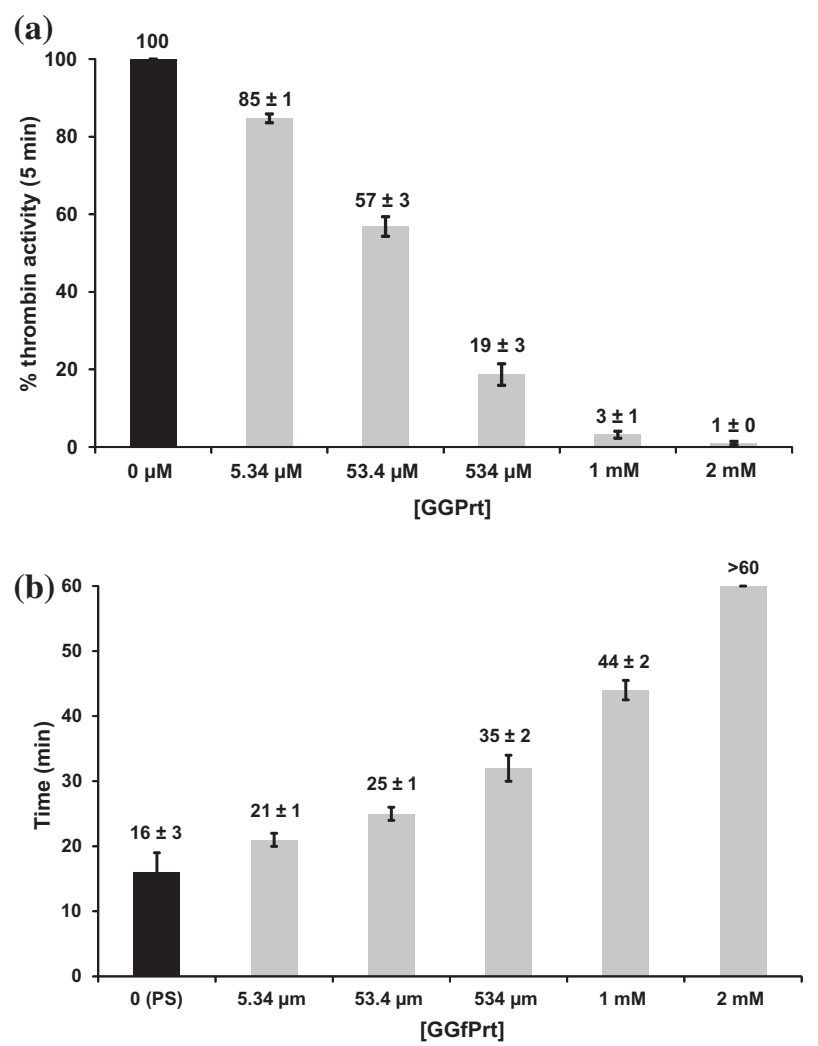

Fig. 1. GGfPrt effect in solution on (a) thrombin proteolytic activity and (b) plasma clotting time. (a) Thrombin was pre-incubated with the indicated concentrations of inhibitor for $15 \mathrm{~min}$. Inhibition levels were determined by measuring the activity of thrombin against a chromogenic substrate after $5 \mathrm{~min}$ reaction. All results are statistically significantly different. (b) Recalcified plasma was incubated with GGfPrt and absorbance at $405 \mathrm{~nm}$ was measured every $30 \mathrm{~s}$ for $60 \mathrm{~min}$. Clotting time was determined as the time at which a sharp increase in absorbance $(0.02$ units larger than the average of the two previous measurements) was detected. All results are statistically significantly different.

\subsection{Characterization of mixed SAMs}

SAMs prepared from pure EG6-COOH and EG3-terminated thiols and their mixtures were characterized using ellipsometry and IRRAS.

An increase in monolayer thickness with increase of the percentage of EG6-COOH-thiol in solution is shown in Fig. 2a. SAMs thickness had a slight enhancement from 2 to $2.5 \mathrm{~nm}$ when the percentage of EG6-COOH in solution raised from 0 to 60, followed by a considerable thickness increase until $4 \mathrm{~nm}$, as the percentage of this thiol was increased from 60 to 100 .

The relationship between the incorporation of the EG6-COOHthiol on the monolayer and its percentage in solution is represented in Fig. 2b. The percentage of $\mathrm{COOH}$ on the monolayer was calculated based on SAMs thickness using the following equation [42]:

EG6 $-\mathrm{COOH}_{\text {Surface }}(\%)=\frac{T_{\text {mixed }} \mathrm{SAM}-T_{\text {pure }} \mathrm{EG} 3}{\Delta T_{\text {pure }}(\mathrm{EG} 6-\mathrm{COOH}-\mathrm{EG} 3)} \times 100$

where EG6- $\mathrm{COOH}_{\text {surface }}(\%)$ is the percentage of the EG6-COOH in a mixed SAM with a thickness $\mathrm{T}_{\text {mixed }} \mathrm{SAM}, \Delta \mathrm{T}_{\text {pure }}(\mathrm{EG} 6-\mathrm{COOH}-\mathrm{EG} 3)$ is the difference between the thickness of EG6-COOH and EG3-terminated pure SAMs ( 4 and $2 \mathrm{~nm}$, respectively). The chemisorption of the EG3-thiol was favourable when compared to EG6-COOH-thiol, since for an equimolar solution of both thiols, there was a predominance of EG3 on the monolayer (72-86\%).

IRRAS was performed to analyse the degree of crystallinity and molecular orientation of ethylene glycol (EG) groups on SAMs (Fig. 3). A strong absorption band at $1130 \mathrm{~cm}^{-1}$ assigned to the $\mathrm{C}-\mathrm{O}-\mathrm{C}$ stretching mode along with a broad shoulder at
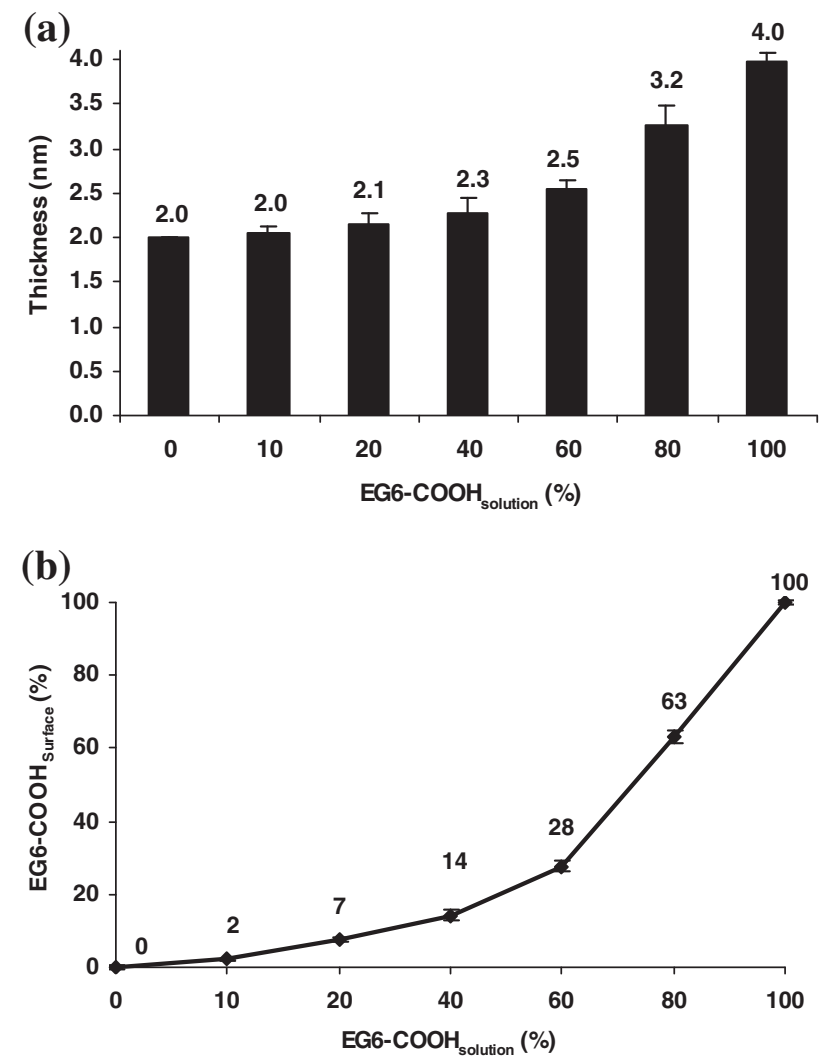

Fig. 2. Characterization of SAMs prepared with different percentages of EG6-COOH thiol. (a) Thickness of SAMs determined by ellipsometry; (b) correlation between the percentage of EG6-COOH-thiol in solution and on the surface. Values were estimated using Eq. (2). 


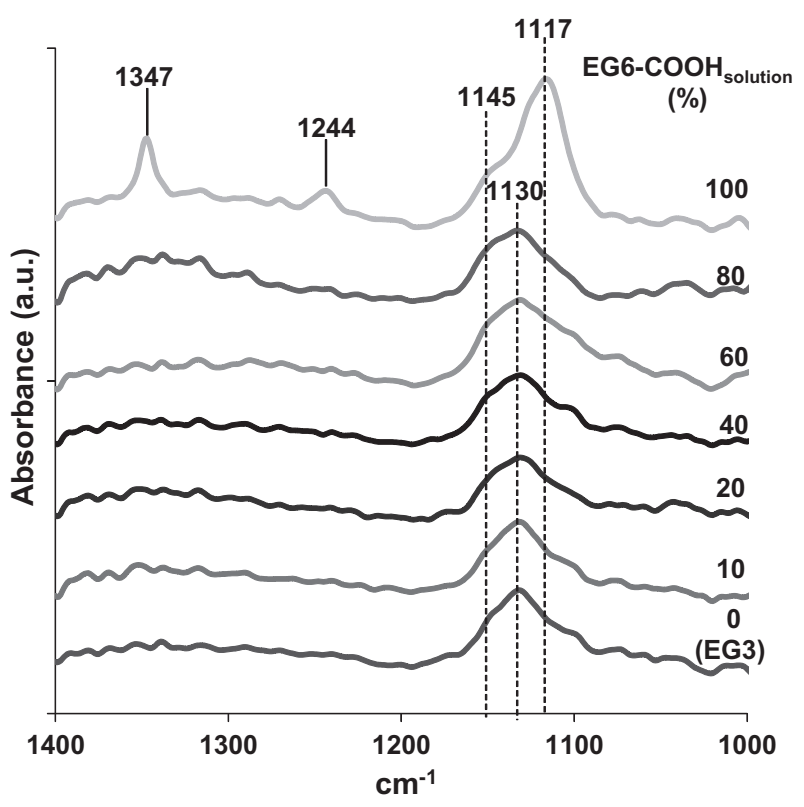

Fig. 3. FTIR-IRRAS spectral region from 1000 to $1400 \mathrm{~cm}^{-1}$ of mixed SAMs (EG fingerprint region).

$\sim 1145 \mathrm{~cm}^{-1}$ was observed in all SAMs prepared with EG3 (pure and mixed SAMs), which is a characteristic of amorphous EG moieties [27]. In the case of 100\% EG6-COOH-SAMs, the absorption band allocated to the $\mathrm{C}-\mathrm{O}-\mathrm{C}$ stretching mode was shifted to $1117 \mathrm{~cm}^{-1}$, which, in combination with absorption bands at 1244 and $1347 \mathrm{~cm}^{-1}$ assigned to $\mathrm{CH}_{2}$ twist and wagging modes, respectively, can be attributed to an oriented crystalline helical phase $[27,43]$. Nevertheless, the broad shoulder at $1145 \mathrm{~cm}^{-1}$ on this SAM suggested an amorphous phase. Thus, domains of oriented helical crystalline phase coexist with an amorphous phase in 100\% EG6-COOH-SAMs, as described elsewhere [43]. The orientation of the alkyl chains relative to the surface can be deduced from the relative intensities of their $\mathrm{CH}_{2}$-stretching vibrations, detected in infrared region from 2800 to $3000 \mathrm{~cm}^{-1}$. A crystalline helical conformation with high packing density has a characteristic strong $\mathrm{CH}$ stretching peak at $2892 \mathrm{~cm}^{-1}$. All pure and mixed SAMs presented a broad band from $\sim 2840$ to $2960 \mathrm{~cm}^{-1}$ (data not shown), suggesting an amorphous and less oriented conformation of EG groups on gold. This type of conformation of EG onto SAMs was described to be responsible for its non-fouling characteristics, namely for its protein adsorption resistance [27].

Although SAMs prepared from a solution with $5 \%$ and $10 \%$ of EG6-COOH did not show thickness differences with regard to pure EG3-SAMs, the incorporation of EG6-COOH below $10 \%$ was referred to in the literature as ideal for the biological activity of immobilized ligands $[42,44-46]$. Therefore, SAMs prepared from solutions containing $5 \%, 20 \%$ and $80 \%$ of EG6-COOH were used for posterior GGfPrt immobilization and subsequent assays.

\subsection{GGfPrt immobilization on mixed SAMs}

The immobilization of the peptide GGfPrt on SAMs was followed using IRRAS and XPS. For simplicity, mixed SAMs are referred through the text with a nomenclature that represents the percentage of the EG6-COOH used in solution.

IRRAS spectra of each GGfPrt immobilization step onto SAMs prepared with $80 \%$ EG6-COOH-thiol are illustrated in Fig. 4. After treatment with EDC and NHS, an absorption band centred at $1746 \mathrm{~cm}^{-1}$, characteristic of the $\mathrm{C}=\mathrm{O}$ stretch of the NHS ester

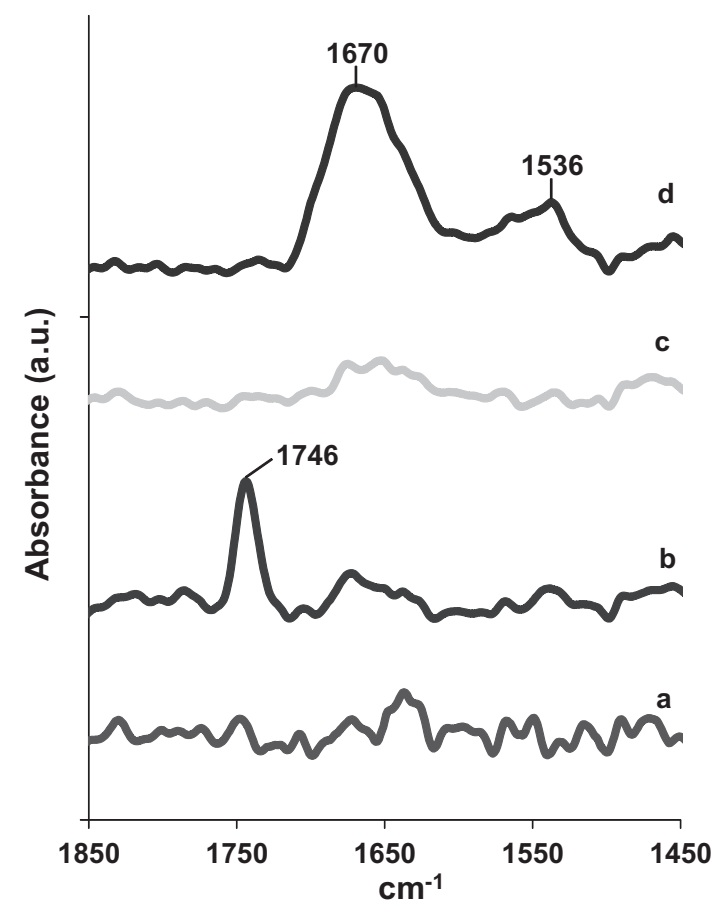

Fig. 4. FTIR-IRRAS spectra of $80 \%$ EG6-COOH-SAMs before (a) and after treatment with NHS and EDC (b), followed by $24 \mathrm{~h}$ incubation in buffer (c) or incubation in 1 mM GGfPrt solution (d).

groups, was observed $[47,48]$. After incubation with peptide, the characteristic absorption bands of the peptide bonds (amide I at $1690 \pm 45 \mathrm{~cm}^{-1}$ and amide II at $1540 \pm 60 \mathrm{~cm}^{-1}$ ) [49] were detected. Simultaneously, the $1746 \mathrm{~cm}^{-1}$ NHS band disappeared, suggesting total reaction with the peptide. Additionally, activated NHS-SAMs incubated in buffer (without peptide) did not present the peak assigned to NHS, suggesting ester hydrolysis back to free COOH groups. Adsorption of GGfPrt to non-activated SAMs was not detected by IRRAS (data not shown), indicating that all the immobilized peptide was covalently bound to the activated SAMs. Similar results were obtained for peptide immobilization onto 20\% EG6-COOH-SAMs. However, peptide immobilization onto 5\% EG6-COOH-SAMs was not detected using this technique (data not shown).

Surface atomic composition of the different SAMs was determined by XPS. The ratio between nitrogen and gold (N/Au) of SAMs prepared with $5 \%, 20 \%$ and $80 \%$ of EG6-COOH in solution, after NHS activation and after incubation in buffer with and without GGfPrt,

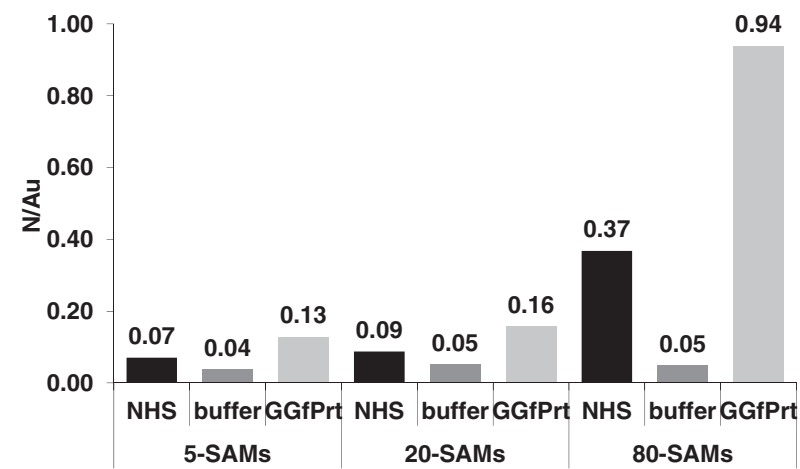

Fig. 5. Ratio between nitrogen and gold $(\mathrm{N} / \mathrm{Au})$ of mixed SAMs after NHS activation (NHS-SAMs) and after immersion in buffer with or without GGfPrt (GGfPrt-SAMs and buffer-SAMs, respectively). 
is shown in Fig. 5. The presence of nitrogen on NHS-SAMs demonstrated the conversion of surface carboxyls into the respective NHS esters. After immersion in buffer, the amount of nitrogen decreased to a residual value, indicating that the pre-formed NHS esters were hydrolysed back to their carboxyl precursors. When incubated with GGfPrt, N/Au increased with regard to buffer-SAMs and NHS-SAMs, demonstrating the success of peptide immobilization. The amount of immobilized GGfPrt was $\sim 7$ and 6 times higher on $80 \%$ EG6-COOH SAMs than on 5\% and 20\% EG6-COOH SAMs, respectively. The absence of nitrogen on mixed SAMs without the EDC/NHS activation step and immersed in GGfPrt (data not shown) indicates the absence of adsorbed GGfPrt.

\subsection{Protein adsorption studies}

Thrombin adsorption was much lower in all SAMs when compared to gold (Fig. 6a). However, thrombin adsorption to SAMs increased with GGfPrt immobilized in low amounts (GGfPrt-5 and GGfPrt-20-SAMs). A high concentration of immobilized GGfPrt (GGfPrt-80-SAMs) was not related to an increase of thrombin adsorption.

When adsorption was performed in the presence of serum proteins, thrombin adsorption was even lower in all SAMs and gold, demonstrating their lack of selectivity for thrombin.

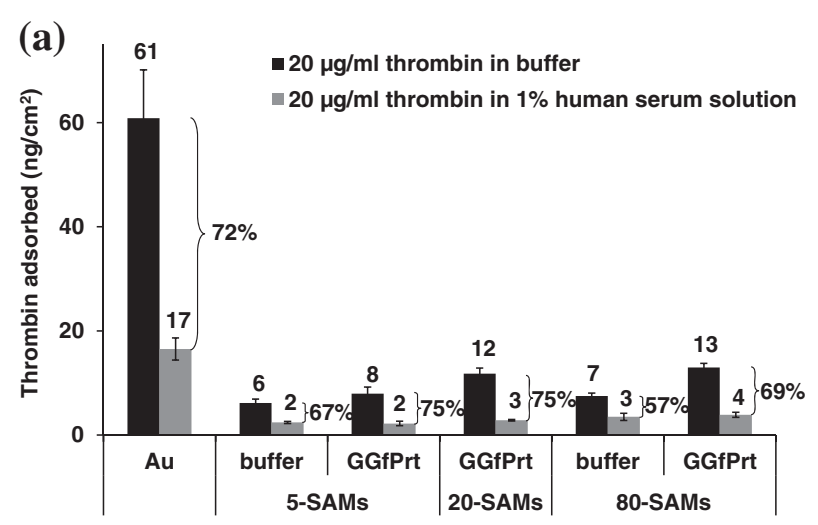

(b)

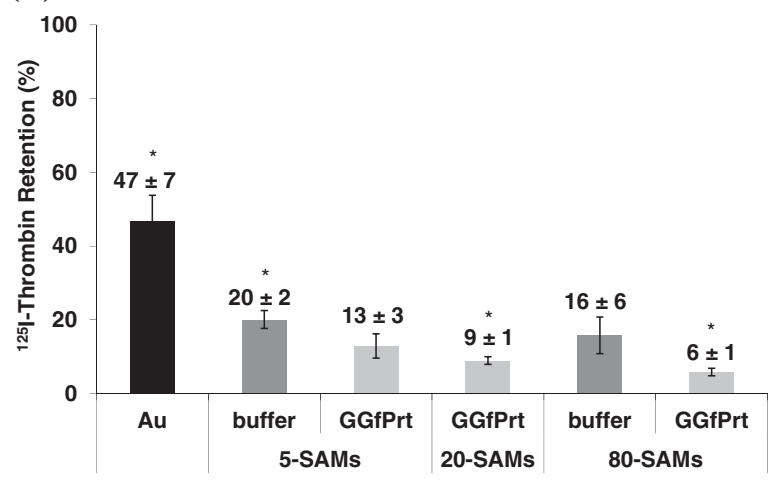

Fig. 6. (a) ${ }^{125}$ I-thrombin adsorption on gold and SAMs with or without immobilized GGfPrt from a pure thrombin solution and from 1\% human serum solution $\left(20 \mu \mathrm{g} \mathrm{ml}^{-1}\right.$ thrombin). Percentages indicate the decrease of adsorbed thrombin due to the presence of serum proteins. The difference in the amount of thrombin adsorbed from buffer is statistically significant between Au and other surfaces, GGfPrt-SAMs and related buffer-SAMs and GGfPrt-5-SAMs and GGfPrt-20-SAMs. Thrombin adsorbed from serum is statistically significantly different between $A u$ and other surfaces and between different GGfPrt-SAMs. (b) Retention of ${ }^{125} \mathrm{I}$ thrombin previously adsorbed on gold and SAMs with or without immobilized GGfPrt, after $24 \mathrm{~h}$ incubation in human serum. *Statistically significant difference compared to all other conditions.
The exchangeability of adsorbed thrombin with serum proteins is presented in Fig. 6b. Thrombin retention was very low in all SAMs, mainly in the presence of immobilized GGfPrt, where thrombin retention decreased as the peptide concentration increased.

Regarding albumin adsorption, immobilized GGfPrt increased albumin adsorption to SAMs in a concentration-dependent manner (Fig. 7a). Albumin adsorption onto surfaces with peptide did not decrease in the presence of plasma proteins as was observed for the control surfaces (Au and 80-EG6-COOH without peptide), a strong indication that albumin binds to GGfPrt-surfaces in a specific way. Moreover, albumin also adsorbs onto surfaces presenting a high number of $-\mathrm{COOH}$ groups (without peptide), as previously described by us [31]. However, the presence of competitive plasma proteins decreased albumin adsorption to 80-EG6-COOH, demonstrating that, on these surfaces, adsorption was non-specific. Even more, albumin adsorption on GGfPrt-SAMs increased when incubated with plasma, indicating an elevated selectivity of immobilized GGfPrt to albumin. The increase in HSA adsorption from protein mixtures or plasma when compared to pure solution was also observed on other albumin-surface systems [30,33,50,51]. This was explained by the increase in total protein concentration that may lead to preferential adsorption of HSA [33,50]. The exchangeability of already adsorbed albumin by other proteins
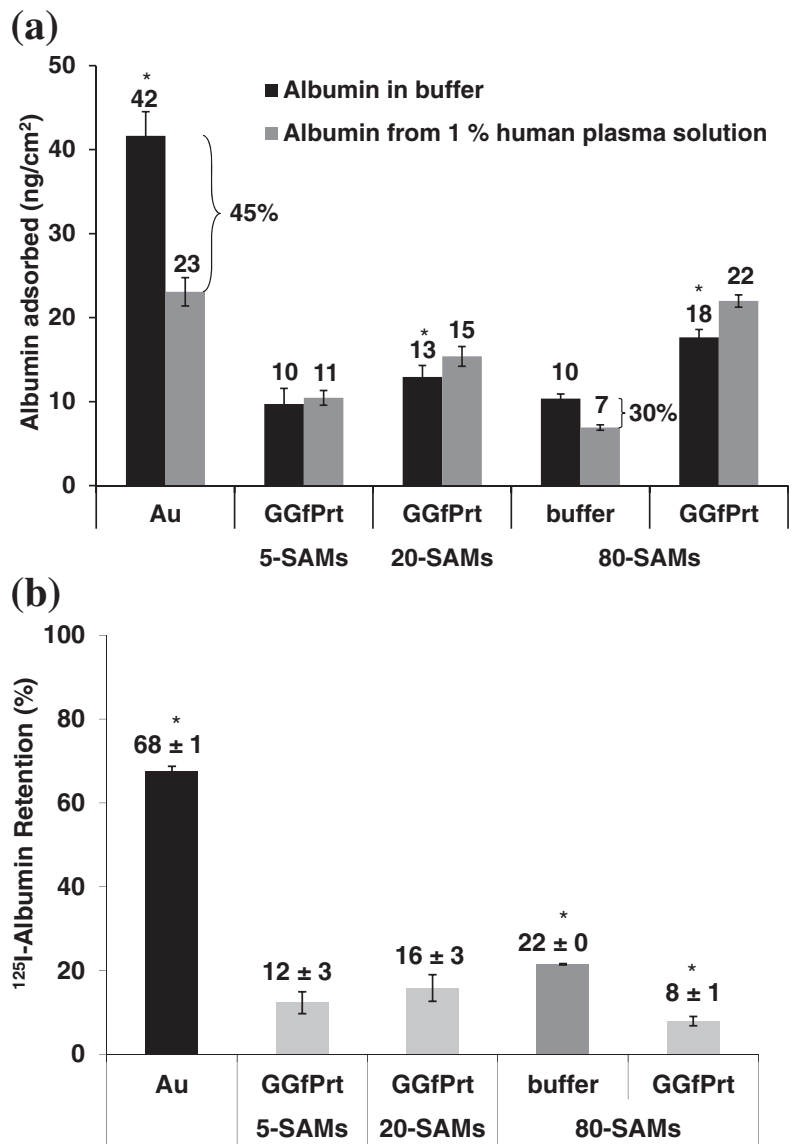

Fig. 7. (a) ${ }^{125}$ I-HSA adsorption on different surfaces from pure albumin solution and from a $1 \%$ human plasma solution $\left(400 \mu \mathrm{g} \mathrm{ml}^{-1}\right.$ albumin). Percentages designate the reduction of adsorbed albumin due to the presence of plasma proteins. *Statistically significant difference compared to all other conditions for albumin adsorbed from pure solution. All conditions are statistically significantly different between them for albumin adsorbed from $1 \%$ plasma solution. (b) Retention of ${ }^{125} \mathrm{I}$ albumin previously adsorbed to gold and SAMs with or without immobilized GGfPrt, after incubation in human plasma $\left(24 \mathrm{~h}, 37^{\circ} \mathrm{C}\right) .{ }^{*}$ Statistically significant difference compared to all other conditions. 
present in the plasma medium (namely albumin) was higher on GGfPrt-SAMs than on the other surfaces (Fig. 7b).

\subsection{Activity of surface adsorbed thrombin}

The activity of adsorbed thrombin against a chromogenic substrate was very low in all the surfaces except on SAMs with higher amounts of GGfPrt (GGfPrt-80-SAMs) (Fig. 8a and b). Thrombin activity was higher when was adsorbed on GGfPrt-SAMs, especially in high peptide concentration (GGfPrt-80-SAMs). The activity of adsorbed thrombin on all GGfPrt-SAMs was $>100$ times higher than in solution. In opposition, when adsorbed on gold, thrombin loses $74 \%$ of its activity compared to the free protease.

Activity of adsorbed thrombin was also evaluated by measuring the fibrinogen clotting time. Fig. 9a shows that thrombin adsorbed on gold and GGfPrt-80-SAMs was able to cleave fibrinogen in a very short time ( 7 and $3 \mathrm{~min}$, respectively). In opposition, thrombin adsorbed onto GGfPrt-20-SAMs had the longest fibrinogen clotting time ( $43 \mathrm{~min}$ ) suggesting that the adsorbed thrombin might be in an arrangement that avoids cleavage of fibrinogen. Moreover, fibrinogen clotting time normalized to the amount of adsorbed thrombin (Fig. 9b) demonstrated that the rate of this protease to cleave fibrinogen is similar when adsorbed onto GGfPrt-5-SAMs and GGfPrt-20-SAMs.

\subsection{Recalcified plasma clotting time assay}

Plasma recalcified clotting time assay evaluates the tendency of a biomaterial to induce coagulation by the adsorption of contact activation proteins (intrinsic pathway). From a biomaterials perspective, this assay is performed without any kind of procoagulant agents (FXII activator and phospholipids), which are required in
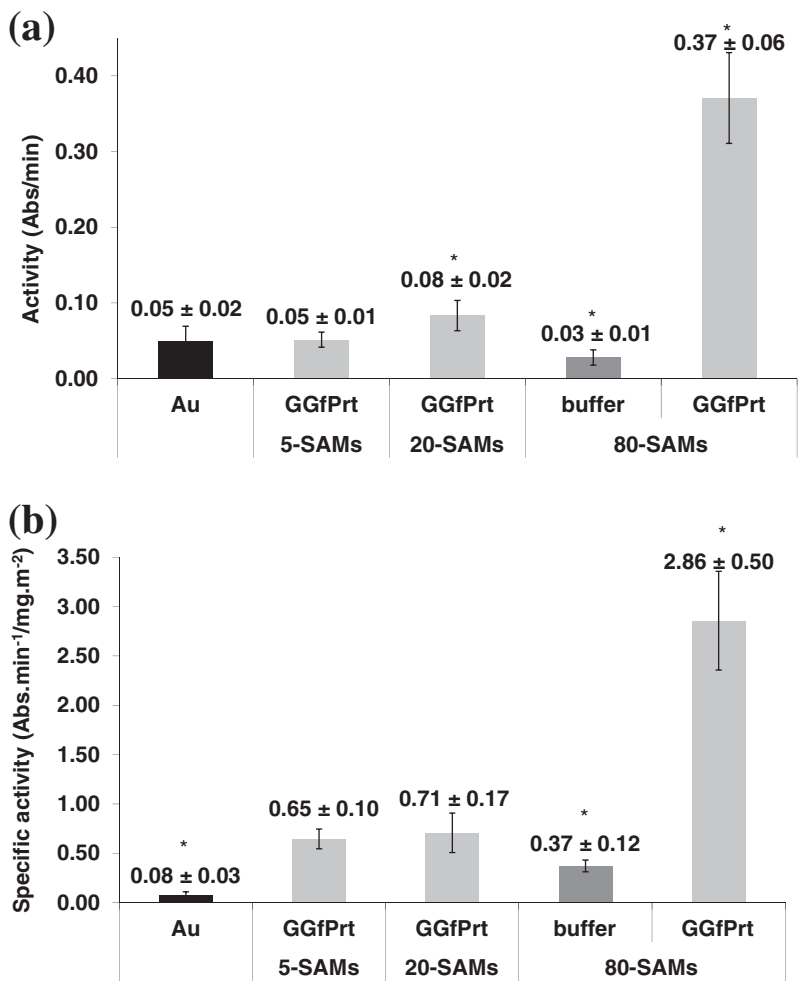

Fig. 8. (a) Hydrolytic activity of adsorbed thrombin towards a chromogenic substrate. *Statistically significant difference compared to all other conditions. (b) Thrombin activity normalized to the quantity of adsorbed thrombin (ratio between rate of reaction (absorbance $\left.\mathrm{min}^{-1}\right)$ and adsorbed thrombin $\left(\mathrm{mg} \mathrm{m}^{-2}\right)$ ). ${ }^{*}$ Statistically significant difference compared to all other conditions.
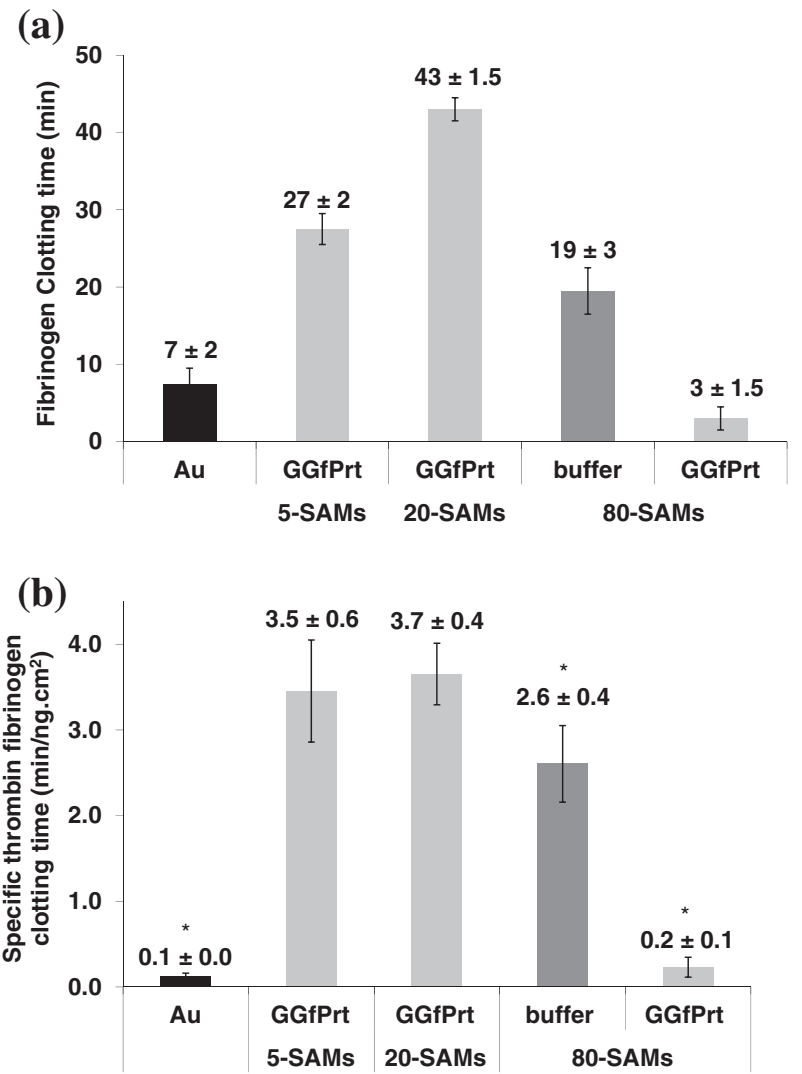

Fig. 9. (a) Fibrinogen clotting time induced by thrombin pre-adsorbed on different surfaces. All conditions are statistically significantly different between them. (b) Thrombin hydrolytic activity towards fibrinogen normalized to the quantity of adsorbed thrombin (ratio between fibrinogen clotting time (min) and adsorbed thrombin $\left.\left(\mathrm{ng} \mathrm{cm}^{-2}\right)\right)$. *Statistically significant difference compared with all other conditions.

other coagulation assays (i.e. activated partial thromboplastin time assay), since these compounds could mask the effect of the biomaterial $[40,52,53]$.

Since this assay was performed with surfaces inserted in nontreated polystyrene (PS) 96-well plates, the clotting time is bound to be affected by the PS surface. Then, PS wells without substrates were used as the negative control $(20 \pm 0.5 \mathrm{~min}$ ) (Fig. 10). GGfPrtSAMs have clotting times similar to PS, showing that GGfPrt avoids the activation of the coagulation system induced by GGfPrt-free surfaces (gold and buffer-80-SAMs). The clotting time of plasma on PS wells was different in the experiments with peptide in

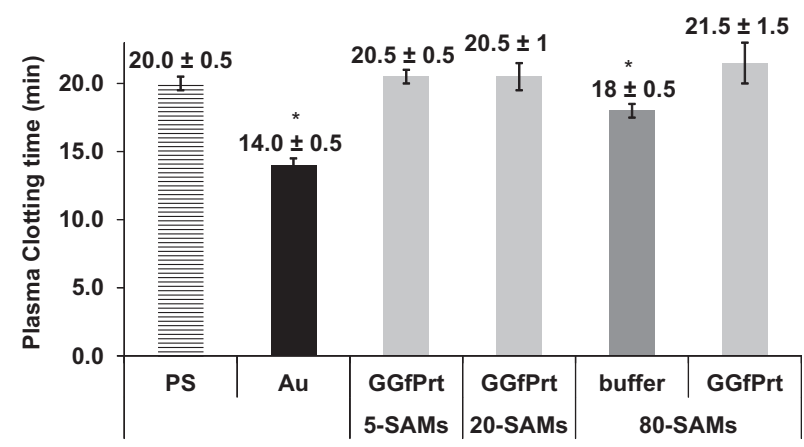

Fig. 10. Clotting time of recalcified plasma in non-treated polystyrene 96 -well plate (PS) in the presence of gold and SAMs. *Statistically significant difference compared to all other conditions. 
solution and surface-bound. It cannot be excluded that the observed differences between assays were due to the previously reported variability of different plasma lots [54,55].

\section{Discussion}

D-Phe-Pro-D-Arg-D-Thr- $\mathrm{CONH}_{2}$ (fPrt), recently described as a potent direct thrombin inhibitor [22,24], with an inhibition constant (Ki) of $0.92 \mu \mathrm{M}$ [23], was evaluated for its capacity to be used as a coating to avoid biomaterials-induced coagulation. This peptide was covalently bound to nanostructured surfaces specifically designed to control its orientation, exposure and density at a molecular level. To ensure correct peptide orientation, i.e. maintaining available the amino acids that directly interact with the active site of thrombin, fPrt must be coupled by its N-terminus. For that, SAMs with different percentages of $\mathrm{COOH}$ groups were prepared using mixtures of two alkanethiols, EG6-COOH- and EG3-thiols, as described by Lahiri et al. [42]. Following activation with NHS/EDC in aqueous buffer at $\mathrm{pH} 8$, the reactive NHS ester groups selectively react with the N-terminus of the peptide: GGfPrt immobilization through the peptide's arginine side chain or through both this side chain and the N-terminal amine is rather unlikely, since the arginine side chain (pKa 12) is still protonated at $\mathrm{pH} 8$, thus not being a strong enough nucleophile to compete with the terminal amine ( $\mathrm{pKa} 7.6-8$ ) for nucleophilic addition to the surface's reactive NHS ester groups.

To increase peptide exposure from the surface, these mixed SAMs were prepared using $\mathrm{COOH}$-thiols with a longer chain length than EG3-thiol. In addition, fPrt was synthesized with two glycine residues attached to the $\mathrm{N}$-terminus to act as a small spacer (GGfPrt). The percentage of EG6-COOH incorporation was used to control GGfPrt surface density and the EG groups to avoid non-specific protein adsorption [56]. The incorporation of $\mathrm{COOH}$ groups on SAMs was confirmed using ellipsometry, which demonstrated that EG3 chemisorbs preferentially on gold surfaces compared to EG6$\mathrm{COOH}$, contrary to what has been previously described [42]. An explanation could reside in the different containers used in SAMs preparation, since it is known that different alkanethiols could adsorb differently to the container used. During this work, polypropylene flasks were used instead of glass scintillation vials employed by Lahiri et al. [42]. Our results were reproducible for all assays (three replicates of each condition in seven assays). The amorphous and less oriented conformation of the EG groups, necessary to avoid non-specific protein adsorption [27], was demonstrated using IRRAS.

GGfPrt was immobilized onto SAMs prepared from solutions with $5 \%, 20 \%$ and $80 \%$ of EG6-COOH. The amount of immobilized GGfPrt was about seven and six times higher on GGfPrt-80-SAMs than on GGfPrt-5 and GGfPrt-20-SAMs, respectively.

The success of GGfPrt immobilization was demonstrated by IRRAS and XPS. Both techniques were able to detect the conversion of $\mathrm{COOH}$ groups in NHS ester and the subsequent GGfPrt coupling by the appearance of the characteristic absorption bands of NHS and peptide (IRRAS) and the increase of the nitrogen amount (XPS).

GGfPrt adsorption was not detected after incubation of nonactivated SAMs in GGfPrt solution, suggesting that all the peptide that was found on activated SAMs was covalently coupled. The presence of NHS groups after the incubation of activated SAMs in buffer was residual, demonstrating the absence of free activated groups that could induce non-specific protein adsorption.

Thrombin adsorption on SAMs was very low when compared to bare gold surface, but always well above the detection limit of the technique used $\left(0.05 \mathrm{ng} \mathrm{cm}^{-2}\right)$ [34,57]. Thrombin adsorption on SAMs corresponds to less than $5 \%$ of the theoretical maximum for a thrombin monolayer, which was estimated to be between
271 and $301 \mathrm{ng} \mathrm{cm}^{-2}$ for molecules lying perpendicular or parallel to the surface [58]. This lower thrombin adsorption can be related to the non-fouling nature of the EG3 background, which can counteract the uptake of the protein of interest as described in other protein-surface systems [40,59-61]. Immobilization of GGfPrt in higher concentrations did not increase thrombin adsorption since although GGfPrt-80-SAMs have six times more peptide than GGfPrt-20-SAMs, the amount of adsorbed thrombin was similar ( $13 \pm 0.8$ and $12 \pm 1.1 \mathrm{ng} \mathrm{cm}^{-2}$, respectively). This can be related to the higher density of immobilized peptides, leading to (a) peptide aggregation with consequent loss of their availability to bind thrombin and/or (b) steric hindrance by peptide-bound thrombin, making free adjacent peptides unavailable for binding to more thrombin molecules [44].

It was also demonstrated that immobilized GGfPrt loses its selectivity to bind thrombin, since when adsorption was performed in the presence of serum proteins, the amount of adsorbed thrombin decreased by $\sim 70 \%$.

In solution, GGfPrt was able to inhibit thrombin proteolytic activity and delay plasma coagulation in a concentration-dependent way. However, its thrombin inhibitory capacity was 10 times lower than that of the peptide without the two glycines (data not shown). After immobilization, GGfPrt improved the hydrolytic activity of adsorbed thrombin towards the small chromogenic substrate, $n$ - $p$-tosyl-Gly-Pro-Arg- $p$-nitroanilide, when compared to the soluble form (>100 times). Although adsorbed in the same concentration, thrombin adsorbed on GGfPrt-80-SAMs was approximately four times more active at cleaving the chromogenic substrate than when adsorbed on GGfPrt-20-SAMs. This could be related with the high peptide density that could lead to a secondary binding (i.e. non-active site directed), thereby exposing catalytically active thrombin molecules. Moreover, thrombin adsorbed onto GGfPrt-80-SAMs had the lowest fibrinogen clotting time in opposition to thrombin adsorbed on GGfPrt-20-SAMs and GGfPrt-5-SAMs that presented the highest fibrinogen clotting time. These results revealed that the enzymatic profile of adsorbed thrombin is dependent on GGfPrt concentration, highlighting the importance of the ligand surface density for the optimal ligandbiomolecule binding as described for other applications [18,42,62-64].

In contrast to SAMs with GGfPrt, bare gold surface adsorbs elevated concentrations of thrombin, in a non-selective and nonreversible way. Thrombin adsorbed on gold has low enzymatic activity to the chromogenic substrate, which has been associated with its adsorption in a random orientation and with an alteration of its conformation after adsorption on gold that can hinder its catalytic centre and not to the specific blocking of its active site $[18,40]$. However, thrombin adsorbed on gold can cleave fibrinogen into fibrin in a very short time, indicating that some thrombin molecules are adsorbed in an orientation that favours the interaction with fibrinogen. Regarding buffer-80-SAMs (without GGfPrt), adsorbed thrombin has a low enzymatic activity against the chromogenic substrate, which can also be attributed to its non-specific adsorption on the $\mathrm{COOH}$ groups of buffer-80-SAM in an orientation that hinders its catalytic centre. However, fibrinogen clotting time of this surface (buffer-80-SAM) was lower than GGfPrt-5 and GGfPrt-20-SAMs but much higher than gold and GGfPrt-80-SAMs. It is likely that thrombin's natural substrate, fibrinogen, can outcompete the $\mathrm{COOH}$ groups of buffer-80-SAM for thrombin binding, as fibrinogen must bind to thrombin's positively charged exosite I for proper processing. Buffer-80-SAMs presented higher fibrinogen clotting time than gold, indicating that these surfaces had fewer molecules of thrombin able to cleave fibrinogen, in good agreement with the amount of total thrombin adsorbed onto Buffer80 -SAMs being much lower than in the gold surface ( 9 times less; Fig. 6). 
Nevertheless, immobilized GGfPrt avoided the decrease of plasma clotting time observed with GGfPrt-free surfaces ( $\mathrm{Au}$ and buffer-80-SAMs) and with other biomedical reference materials such as medical grade poly(ether urethane), poly(ethylene terephthalate) or poly(dimethyl siloxane) [33]. Since it was observed that GGfPrt-SAMs did not bind thrombin in a selective way, the delay on plasma clotting time can be explained by the adsorption of other proteins such as albumin, which are not involved in the activation of the coagulation system. Immobilized GGfPrt induces albumin adsorption on SAMs in a selective and reversible way. The selectivity of GGfPrt to albumin can be explained by the albumin ability to bind threonine [65], the terminal amino acid of GGfPrt. Surfaces that adsorb albumin in a selective and reversible way avoid the adsorption of blood contact proteins (FXII, high molecular weight kininogen (HMWK) and prekallikrein (PK)) that trigger the intrinsic coagulation and also the adsorption of adhesive proteins such as fibrinogen that mediate platelet adhesion and aggregation $[33,63,66]$. Furthermore, surfaces coated with albumin have been found to reduce platelet and leukocyte adhesion and aggregation to synthetic materials, preventing subsequent thrombus formation in vitro [67]. However, pre-coating a biomaterial with albumin has several disadvantages, namely: (1) denaturation on the surface, being recognized as an altered protein; (2) desorption, exposing the bare surface to activate coagulation and related processes; (3) conformational changes, exposing groups that induce coagulation; (4) exchange by other proteins that are involved in coagulation [68]. The development of surfaces that can attract and bind albumin from the bloodstream in a selective and reversible way has been the focus of several researchers as a way to increase the haemocompatibility of biomaterials [66,69,70]. Albumin adsorption studies showed that GGfPrt surfaces adsorb albumin in a selective and reversible way, suggesting increased haemocompatibility.

The decrease of plasma clotting time induced by the gold surface when compared to the control (PS) was related with the adsorption/activation of blood contact proteins, such as HMWK $[55,61]$ and FXII [55]. COOH groups can bind the contact proteins HMWK, FXII and PK [71], which explain the faster plasma clotting time of buffer-80-SAMs with regard to the control (PS).

This work demonstrated that after surface immobilization, GGfPrt lost its capacity to bind and inactivate the procoagulant activity of thrombin, but opens new perspectives for its utilization as a biomaterial coating due to its high selectivity to albumin, since surfaces that adsorb albumin in a selective and reversible way are described to avoid biomaterials-induced thrombus formation.

\section{Conclusion}

GGfPrt, a small thrombin inhibitor peptide, was successfully synthesized and immobilized in different concentrations on COOH-EG6/EG3 mixed SAMs. It was demonstrated that, after immobilization, GGfPrt avoids the coagulation activation induced by GGfPrt-free SAMs, due to the adsorption of albumin, a protein that is not involved in the activation of the coagulation system, in a selective and reversible way. This work opens new outlooks to improve the haemocompatibility of biomaterials.

\section{Disclaimer}

No benefit of any kind will be received either directly or indirectly by the authors.

\section{Acknowledgements}

This work was financed by FEDER funds through the Programa Operacional Factores de Competitividade (COMPETE) and by
Portuguese funds through FCT (Fundação para a Ciência e a Tecnologia) in the framework of the projects PTDC/BIA-PRO/70627/2006 and PEst-C/SAU/LA0002/2011. The authors would like to thank to Doctor Carlos Sá and Liliana Alves (CEMUP) for assistance in the XPS investigation and IPS for donating the human plasma. Sidónio Freitas acknowledges FCT for PhD fellowship SFRH/BD/40537/ 2007.

\section{References}

[1] Gorbet MB, Sefton MV. Biomaterial-associated thrombosis: roles of coagulation factors, complement, platelets and leukocytes. Biomaterials 2004;25:5681-703.

[2] Bode W. Structure and interaction modes of thrombin. Blood Cells Mol Dis 2006;36:122-30.

[3] Murugesan S, Xie J, Linhardt RJ. Immobilization of heparin: approaches and applications. Curr Top Med Chem 2008;8:80-100.

[4] Kidane AG, Salacinski H, Tiwari A, Bruckdorfer KR, Seifalian AM. Anticoagulant and antiplatelet agents: their clinical and device application(s) together with usages to engineer surfaces. Biomacromolecules 2004;5:798-813.

[5] Ranucci M, Balduini A, Ditta A, Boncilli A, Brozzi S. A systematic review of biocompatible cardiopulmonary bypass circuits and clinical outcome. Ann Thorac Surg 2009;87:1311-9.

[6] Laux V, Perzborn E, Heitmeier S, Von Degenfeld G, Dittrich-Wengenroth E, Buchmüller A, et al. Direct inhibitors of coagulation proteins-the end of the heparin and low-molecular-weight heparin era for anticoagulant therapy? Thromb Haemost 2009;102:892-9.

[7] Chen H, Yuan L, Song W, Wu Z, Li D. Biocompatible polymer materials: role of protein-surface interactions. Prog Polym Sci 2008;33:1059-87.

[8] Lee CJ, Ansell JE. Direct thrombin inhibitors. $\mathrm{Br} J$ Clin Pharmacol $2011 ; 72: 581-92$.

[9] Phaneuf MD, Berceli SA, Bide MJ, Quist WC, LoGerfo FW. Covalent linkage of recombinant hirudin to poly(ethylene terephthalate) (Dacron): creation of a novel antithrombin surface. Biomaterials 1997; 18:755-65.

[10] Seifert B, Romaniuk P, Groth T. Covalent immobilization of hirudin improves the haemocompatibility of polylactide-polyglycolide in vitro. Biomaterials 1997; 18:1495-502.

[11] Berceli SA, Phaneuf MD, LoGerfo FW, Patterson RB. Evaluation of a novel hirudin-coated polyester graft to physiologic flow conditions: hirudin bioavailability and thrombin uptake. J Vasc Surg 1998;27:1117-27.

[12] Phaneuf MD, Szycher M, Berceli SA, Dempsey DJ, Quist WC, LoGerfo FW Covalent linkage of recombinant hirudin to a novel ionic poly(carbonate) urethane polymer with protein binding sites: determination of surface antithrombin activity. Artif Organs 1998;22:657-65.

[13] Wyers MC, Phaneuf MD, Rzucidlo EM, Contreras MA, Logerfo FW, Quist WC. In vivo assessment of a novel Dacron surface with covalently bound recombinant hirudin. Cardiovasc Pathol 1999;8:153-9.

[14] Molek P, Strukelj B, Bratkovic T. Peptide phage display as a tool for drug discovery: targeting membrane receptors. Molecules 2011;16:857-87.

[15] Acharya G, Doorneweerd DD, Chang CL, Henne WA, Low PS, Savran CA. Labelfree optical detection of anthrax-causing spores. J Am Chem Soc 2007;129:732-3.

[16] Schwienhorst A. Direct thrombin inhibitors-a survey of recent developments. Cell Mol Life Sci 2006;63:2773-91.

[17] Sun X, Sheardown H, Tengvall P, Brash JL. Peptide modified gold-coated polyurethanes as thrombin scavenging surfaces. J Biomed Mater Res 2000;49:66-78.

[18] Freitas SC, Barbosa MA, Martins MCL. The effect of immobilization of thrombin inhibitors onto self-assembled monolayers on the adsorption and activity of thrombin. Biomaterials 2010;31:3772-80.

[19] Maitz MF, Sperling C, Werner C. Immobilization of the irreversible thrombin inhibitor D-Phe-Pro-Arg- chloromethylketone: a concept for hemocompatible surfaces? J Biomed Mater Res A 2010;94:905-12.

[20] Maraganore JM, Bourdon P, Jablonski J, Ramachandran KL, Fenton Ii JW. Design and characterization of hirulogs: a novel class of bivalent peptide inhibitors of thrombin. Biochemistry 1990;29:7095-101.

[21] Clement CC, Manfred P. Structure-based design and structure-activity relationships of D-Phe-Pro-D-Arg-P1'-CONH2 tetrapeptides inhibitors of thrombin. In: Blondelle SE, editor. Understanding biology using peptides. New York: Springer; 2006. p. 553-4.

[22] Clement CC, Babinska A, Kornecki E, Philipp M. Isothermal titration calorimetry and inhibition of platelets aggregation by [D-Phe/ (transcinnamoyl)-Pro-D-Arg-P1'-CONH2] peptides inhibitors of thrombin. Adv Exp Med Biol 2009;611:579-80.

[23] Figueiredo AC, Clement CC, Zakia S, Gingold J, Philipp M, Pereira PJB. Rational design and characterization of D-Phe-Pro-D-Arg-derived direct thrombin inhibitors. PLoS One 2012;7:e34354.

[24] Carvalho Figueiredo A, Clement CC, Philipp M, Barbosa Pereira PJ. Crystallization and preliminary crystallographic characterization of three peptidic inhibitors in complex with $\alpha$-thrombin. Acta Crystallogr Sect $F$ Struct Biol Cryst Commun 2011;67:54-8.

[25] Bode W, Mayr I, Baumann U, Huber R, Stone SR, Hofsteenge J. The refined $1.9 \AA$ crystal structure of human $\alpha$-thrombin: Interaction with D-Phe-Pro-Arg 
chloromethylketone and significance of the Tyr-Pro-Pro-Trp insertion segment. EMBO J 1989;8:3467-75.

[26] Clement CC, Babinska A, Philipp M. Inhibition of platelets aggregation by [DPhe-Pro-D-Arg-P1'-CONH2] peptides inhibitors of thrombin. FASEB 2007;21:A1013.

[27] Herrwerth S, Eck W, Reinhardt S, Grunze M. Factors that determine the protein resistance of oligoether self-assembled monolayers-internal hydrophilicity, terminal hydrophilicity, and lateral packing density. J Am Chem Soc 2003;125:9359-66.

[28] Fields GB, Noble RL. Solid phase peptide synthesis utilizing 9fluorenylmethoxycarbonyl amino acids. Int J Pept Protein Res 1990:35:161-214.

[29] Collins JM, Leadbeater NE. Microwave energy: a versatile tool for the biosciences. Org Biomol Chem 2007;5:1141-50.

[30] Martins MCL, Ratner BD, Barbosa MA. Protein adsorption on mixtures of hydroxyl- and methyl-terminated alkanethiols self-assembled monolayers. J Biomed Mater Res A 2003;67:158-71.

[31] Martins MCL, Fonseca C, Barbosa MA, Ratner BD. Albumin adsorption on alkanethiols self-assembled monolayers on gold electrodes studied by chronopotentiometry. Biomaterials 2003;24:3697-706.

[32] Iodine-125. A guide to radioiodination techniques. Little Chalfort: Amersham Life Science; 1993.

[33] Gonçalves IC, Martins MCL, Barbosa MA, Ratner BD. Protein adsorption and clotting time of pHEMA hydrogels modified with C18 ligands to adsorb albumin selectively and reversibly. Biomaterials 2009;30:5541-51.

[34] Horbett TA. Techniques for protein adsorption studies. In: Williams DF, editor. Techniques of biocompatibility testing. Boca Raton, FL: CRC Press; 1986. p. $183-214$.

[35] Du YJ, Cornelius RM, Brash JL. Measurement of protein adsorption to gold surface by radioiodination methods: suppression of free iodide sorption. Colloids Surf B Biointerfaces 2000;17:59-67.

[36] Gonçalves IC, Martins MCL, Barbosa MA, Ratner BD. Protein adsorption on 18alkyl chains immobilized on hydroxyl-terminated self-assembled monolayers. Biomaterials 2005;26:3891-9.

[37] Barrias CC, Martins MCL, Miranda MCS, Barbosa MA. Adsorption of a therapeutic enzyme to self-assembled monolayers: effect of surface chemistry and solution $\mathrm{pH}$ on the amount and activity of adsorbed enzyme. Biomaterials 2005;26:2695-704.

[38] Properties of thrombin, Haematologic Technologies Inc.; thrombin specification sheet, 2009 or web locations, <http://www.haemtech.com/ Enzymes/Thrombin.htm> [accessed year 2011].

[39] Ratner BD, Hoffman AF, Schoen FJ, Lemons JL. Biomaterials science - an introduction to materials in medicine. 2nd ed. San Diego, CA: Elsevier/ Academic Press; 2004.

[40] Freitas SC, Cereija TB, Figueiredo AC, Osório H, Pereira PJB, Barbosa MA, et al. Bioengineered surfaces to improve the blood compatibility of biomaterials through direct thrombin inactivation. Acta Biomater 2012;8:4101-10.

[41] Lottenberg R, Christensen U, Jackson CM, Coleman PL. Assay of coagulation proteases using peptide chromogenic and fluorogenic substrates. Methods Enzymol 1981;80(Pt C):341-61.

[42] Lahiri J, Isaacs L, Tien J, Whitesides GM. A strategy for the generation of surfaces presenting ligands for studies of binding based on an active ester as a common reactive intermediate: a surface plasmon resonance study. Anal Chem 1999;71:777-90.

[43] Harder P, Grunze M, Dahint R, Whitesides GM, Laibinis PE. Molecular conformation in oligo(ethylene glycol)-terminated self-assembled monolayers on gold and silver surfaces determines their ability to resist protein adsorption. J Phys Chem B 1998;102:426-36.

[44] Lahiri J, Isaacs L, Grzybowski B, Carbeck JD, Whitesides GM. Biospecifîc binding of carbonic anhydrase to mixed SAMs presenting benzenesulfonamide ligands: a model system for studying lateral steric effects. Langmuir 1999;15:7186-98.

[45] Metallo SJ, Kane RS, Holmlin RE, Whitesides GM. Using bifunctional polymers presenting vancomycin and fluorescein groups to direct anti-fluorescein antibodies to self-assembled monolayers presenting D-alanine-D-alanine groups. J Am Chem Soc 2003;125:4534-40.

[46] Subramanian A, Irudayaraj J, Ryan T. A mixed self-assembled monolayer-based surface plasmon immunosensor for detection of E. coli 0157:H7. Biosensors Bioelectron 2006:21:998-1006.

[47] Wagner P, Hegner M, Kernen P, Zaugg F, Semenza G. Covalent immobilization of native biomolecules onto $\mathrm{Au}(111)$ via N-hydroxysuccinimide ester functionalized self-assembled monolayers for scanning probe microscopy Biophys J 1996;70:2052-66.
[48] Frey BL, Corn RM. Covalent attachment and derivatization of poly(L-lysine) monolayers on gold surfaces as characterized by polarization-modulation FTIR spectroscopy. Anal Chem 1996;68:3187-93.

[49] Roeges NPG. A guide to the complete interpretation of infrared spectra of organic structures. Chichester: Wiley; 1994.

[50] Martins MCL, Naeemi E, Ratner BD, Barbosa MA. Albumin adsorption on Cibacron Blue F3G-A immobilized onto oligo(ethylene glycol)-terminated selfassembled monolayers. J Mater Sci Mater Med 2003;14:945-54.

[51] Martins MCL, Wang D, Ji J, Feng L, Barbosa MA. Albumin and fibrinogen adsorption on PU-PHEMA surfaces. Biomaterials 2003;24:2067-76.

[52] Motlagh D, Yang J, Lui KY, Webb AR, Ameer GA. Hemocompatibility evaluation of poly(glycerol-sebacate) in vitro for vascular tissue engineering. Biomaterials 2006;27:4315-24.

[53] Andrade FK, Silva JP, Carvalho M, Castanheira EMS, Soares R, Gama M. Studies on the hemocompatibility of bacterial cellulose. J Biomed Mater Res A 2011:98:554-66.

[54] Grunkemeier JM, Tsai WB, Horbett TA. Hemocompatibility of treated polystyrene substrates: contact activation, platelet adhesion, and procoagulant activity of adherent platelets. J Biomed Mater Res 1998;41:657-70.

[55] Alibeik S, Zhu S, Yau JW, Weitz JI, Brash JL. Surface modification with polyethylene glycol-corn trypsin inhibitor conjugate to inhibit the contact factor pathway on blood-contacting surfaces. Acta Biomater 2011:7:4177-86.

[56] Prime KL, Whitesides GM. Adsorption of proteins onto surfaces containing end-attached oligo(ethylene oxide): a model system using self-assembled monolayers. J Am Chem Soc 1993;115:10714-21.

[57] Yu XJ, Brash JL. Measurement of protein adsorption to solid surfaces in relation to blood compatibility using radioiodine labelling methods. In: Dawids SG, editor. Test procedures for the blood compatibility of biomaterials. Dordrecht: Kluwer; 1993. p. 287-330.

[58] Weisel JW, Nagaswami C, Young TA, Light DR. The shape of thrombomodulin and interactions with thrombin as determined by electron microscopy. J Biol Chem 1996:271:31485-90.

[59] Chen H, Zhang Y, Li D, Hu X, Wang L, McClung WG, et al. Surfaces having dual fibrinolytic and protein resistant properties by immobilization of lysine on polyurethane through a PEG spacer. J Biomed Mater Res A 2009;90:940-6.

[60] Li D, Chen H, Glenn McClung W, Brash JL. Lysine-PEG-modified polyurethane as a fibrinolytic surface: effect of PEG chain length on protein interactions, platelet interactions and clot lysis. Acta Biomater 2009;5:1864-71.

[61] Sask KN, Zhitomirsky I, Berry LR, Chan AKC, Brash JL. Surface modification with an antithrombin-heparin complex for anticoagulation: studies on a model surface with gold as substrate. Acta Biomater 2010;6:2911-9.

[62] Briand E, Salmain M, Compère C, Pradier CM. Immobilization of Protein A on SAMs for the elaboration of immunosensors. Colloids Surf B Biointerfaces 2006;53:215-24.

[63] Gonçalves IC, Martins MCL, Barbosa MA, Naeemi E, Ratner BD. Selective protein adsorption modulates platelet adhesion and activation to oligo(ethylene glycol)-terminated self-assembled monolayers with C18 ligands. J Biomed Mater Res A 2009;89:642-53.

[64] Martins MCL, Curtin SA, Freitas SC, Salgueiro P, Ratner BD, Barbosa MA. Molecularly designed surfaces for blood deheparinization using an immobilized heparin-binding peptide. J Biomed Mater Res A 2009;88:162-73.

[65] Sarkar B, Wigfield Y. Evidence for albumin-cu(II)-amino acid ternary complex. Can J Biochem 1968:46:601-7.

[66] Gonçalves IC, Martins MCL, Barbosa JN, Oliveira P, Barbosa MA, Ratner BD. Platelet and leukocyte adhesion to albumin binding self-assembled monolayers. J Mater Sci Mater Med 2011:1-11.

[67] Kottke-Marchant K, Anderson JM, Umemura Y, Marchant RE. Effect of albumin coating on the in vitro blood compatibility of Dacron ${ }^{\circledR}$ arterial prostheses. Biomaterials 1989; 10:147-55.

[68] Werner C, Maitz MF, Sperling C. Current strategies towards hemocompatible coatings. J Mater Chem 2007;17:3376-84.

[69] Keogh JR, Eaton JW. Albumin binding surfaces for biomaterials. J Lab Clin Med 1994; $124: 537-45$

[70] Guha Thakurta S, Subramanian A. Evaluation of in situ albumin binding surfaces: a study of protein adsorption and platelet adhesion. J Mater Sci Mater Med 2011;22:137-49.

[71] Lestelius M, Liedberg B, Tengvall P. In vitro plasma protein adsorption on $\omega$ functionalized alkanethiolate self-assembled monolayers. Langmuir $1997 ; 13: 5900-8$. 